\title{
Effect of the Brown Coal-Based Feed Additive on Poultry Productivity Indicators
}

\author{
Boris Khorin", Alexandra Danilova", Natalia Labutina ${ }^{1}$, Denis Yurin ${ }^{1}$, and \\ Natalia Yurina ${ }^{1,2}$ \\ ${ }^{1}$ Krasnodar Research Centre for Animal Husbandry and Veterinary Medicine, Krasnodar, Russian \\ Federation \\ ${ }^{2}$ Federal State Budgetary Educational Institution of Higher Education "Kuban State Agrarian \\ University named after I.T. Trubilin", Krasnodar, Russian Federation
}

\section{ORCID:}

Denis Yurin: http://orcid.org/0000-0003-1517-4858

\section{Abstract}

This study examined the effect of feed additives based on brown coal on the productivity indicators of laying hens. The Relict $A^{\circledR}$ organo-mineral feed additive for livestock and poultry is a multi-component, gummatized product with a wide range of biological activity, accelerating the growth and development of the animal. Relict $A^{\circledR}$ is

Corresponding Author:

Denis Yurin

4806144@mail.ru

Published: 5 April 2021

Publishing services provided by Knowledge E

(c) Boris Khorin et al. This article is distributed under the terms of the Creative Commons

Attribution License, which permits unrestricted use and redistribution provided that the original author and source are credited.

Selection and Peer-review under the responsibility of the DonAgro Conference Committee. an environmentally friendly supplement that does not contain hormones or synthetic compounds. The control group was fed complete feed without additives. The second, third and fourth groups were fed feed containing $0.04 \%, 0.06 \%$ and $0.10 \%$ of the studied additives, respectively. The amount of feed for each group of laying hens was strictly normalized in accordance with their age, according to the recommendations for this cross. The use of the Relict $A^{\circledR}$ feed additive in the laying hens' rations led to an increase in the average number of eggs per laying hen, a decrease in the cost of feed for producing 1 dozen eggs, and a reduction in the time when the poultry reached the peak egg laying intensity. Feeding the additive to laying hens reduced the cost of producing 1 dozen eggs in the experimental groups, and also increased the profitability of chicken eggs in comparison with the control. The best dose was to use $0.06 \%$ of Relict $A^{\circledR}$ by weight of the feed. A $26.6 \%$ increase in laying hen egg production was found.

Keywords: feed additives, laying hens, egg productivity, brown coal.
In Russia, as in other countries of the world, one of the leading agricultural sectors is poultry farming. It provides Russians with high-quality natural food and raw materials for industrial processing (feather, down and litter). The increase in production by the poultry industry is observed annually.

Russia has the largest brown coal resources suitable for complex processing in various technological processes, including semi-coking. These coals are currently mined 
mainly in the Kansk-Achinsky brown coal basin. The 670 billion tons of geological reserves of brown coal are estimated in the Kansk-Achinsk basin to a depth of $600 \mathrm{~m}$. In this case, the 140.4 billion tons can be processed in an open way.

Coal seams, falling into the zone of oxygen, which is in the air and groundwater, are subjected to oxidation. When extracted to the surface, oxidized coal due to the loss of calorie content is a waste of the coal industry. The organic mass of oxidized brown coal is represented mainly by humic acids (70-90\%). Humic acids (HA) are the most extensive class of natural compounds. Humic acids are part of the organic matter of soils, natural waters and solid fossil fuels [1-3].

Humic acids (HA) are substances of a very complex structure, nitrogen-containing hydroxycarboxylic acids. With nuclei and in the side aliphatic chains, HA contain various functional groups. Despite the known elemental composition, HA don't have exact molecular formulas, because relate to compounds of variable composition. With the help of hydrocarbon bonds, HA form chains that form molecules that are naturally folded into a ball. Upon dissolution, a small concentration promotes the unwinding of the polymer chain package and changes the configuration of HA molecules. This accelerates the penetration of HA through cell membranes [4-6].

A distinctive feature of the chemical structure of humic acids $(H A)$, regardless of the source of origin, is the presence of a skeleton in the form of an aromatic carbon skeleton substituted by alkyl and carboxyl, hydroxyl and methoxy groups, and a peripheral part enriched in polysaccharide and polypeptide fragments. Due to this fragment composition, HA fulfill a number of important ecological functions in the biosphere, one of which is the physiological effect. HA isolated from peat, brown coal, soil, composts have high biological activity, in comparison with HA of the soil itself. This is explained by the fact that the functional groups in it, which determine the reactivity, solubility, and biological activity, are blocked by metal cations [7-9].

In peat, the destruction of polysaccharides and proteins, the transition to the liquid phase of activated HA enriched with oxygen-containing functional groups, melanoidins, pectins, amino acids, as a result of oxidation-hydrolytic processes. Preparations obtained using oxidative processes usually turn out to be more active. Promising methods for producing an environmentally friendly biostimulator using preliminary mechanical activation of peat have been proposed.

With intense mechanical impact on peat, significant changes occur in it in the chemical composition of its main components. These changes lead to an increase in the yield of HA, its solubility, as well as an increase in the content of functional groups in it. Accordingly, important properties of HA, in particular, antioxidant activity, are changing. 
As a raw material for producing humic preparations from coal, natural brown coal, natural oxidized brown coal, and mechanochemically oxidized brown coal can be used. It's not known whether more affordable brown coal can be used to produce active humic preparations. Also, it is not known how HA differ from brown coal, oxidized under natural conditions and oxidized mechanochemically [10-12].

The formation of humic substances is the second largest process of transformation organic matter in nature after photosynthesis. Humic substances are the most stable form of organic carbon compounds outside living organisms. Currently, humic substances are recognized as one of the promising areas of «green» chemistry as an affordable and cheap source of raw materials for the production of chemically important products. The use of natural and modified humic preparations such as surfactants, polymers with controlled redox properties (redox polymers), the basis for obtaining new drugs, plant protection products, new sorbents, and remedies for the restoration of territories contaminated with radionuclides, are promising as such products. metals, organic ecotoxicants, oil products, etc.

An urgent task is the search for new raw materials for biologically active substances of natural origin and the development of new bioavailable drugs based on it.

Humic acids stabilize the intestinal flora and thereby provide improved nutrient intake from animal feed. This leads to an increase in live weight of the animal without increasing the amount of food consumed by it. Improving the digestibility of feed, as a result of achieving optimal $\mathrm{pH}$ in the digestive tract, leads to a decrease in nitrogenous emissions and a reduction in unpleasant odors [13-15].

Objective: to study the effect of the feed additive «Relict $A^{\circledR}$ » on productivity of crosscountry Hajseks Brown laying hens.

The objectives of scientific research:

1. to study the safety of the livestock of laying hens;

2. to analyze feed intake through daily group metering;

3. to calculate the cost of feed per unit of production (for the production of 1 dozen chicken eggs);

4. to study egg laying on a medium laying hen - by daily counting of the eggs collected;

5. to determine the dynamics of changes in egg mass and egg mass yield per 1 average laying hen;

6. to study the economic efficiency of the use of feed additives in the feeding of laying hens. 


\section{Methods and Equipment}

A scientific experiment to study the effect of the «Relict $A^{\circledR}$ 》 feed additive produced by Genesis LLC on the productivity of laying hens of the cross Highsex Brown was carried out in a vivarium of the Federal State Scientific Institution "Krasnodar Research Center of Animal Breading and Veterinary Medicine". Four groups of young egg breed chickens were formed at the age of 100 days by the method of pair-analogues for research. The equalization period lasted 10 days. The trial period was 30 days. In each group there were 40 goals. The poultry was kept outdoor in enclosures, on a deep litter with free access to feed and water in accordance with the methodology of the Federal State Budget Scientific Institution, the Federal Research Center "All-Russian Research and Technological Institute of Poultry" (2013). Watering of poultry was carried out using vacuum drinking bowls. In the diets of the experimental groups of hens, the studied supplement was included according to the experimental scheme (Table 1).

TABLE 1: Scheme of scientific experience

Group
1
2
3
4

Number of goals
40

\section{Feeding Features \\ Complete feed (PC) \\ $P C+0.04 \%$ «Relict $A^{{ }}$» by weight of feed \\ $P C+0.06 \%$ «Relict $A^{\circledR} 》$ by weight of feed \\ PC+ $0.10 \%$ «Relict $A^{\circledR} 》$ by weight of feed}

The conditions were the same and consistent with the recommendations of the Federal State Budget Scientific Institution, the Federal Research Center "All-Russian Research and Technological Institute of Poultry" (2013).

The first group (control) was fed complete feed without additives. The second, third and fourth groups in the same feed included $0.04,0.06$ and $0.10 \%$ of the studied additives, respectively. The amount of feed for each group of laying hens was strictly normalized in accordance with its age according to the recommendations for this cross.

The structure of the diet and nutrition for laying hens are presented in Table 2.

According to the manufacturer of the feed, the diet is completely balanced.

LLC NPP Genesis (Novosibirsk, Russian Federation) is the organization that developed the studied feed additive.

The «Relict $A^{\circledR}$ 》 organo-mineral feed additive for livestock and poultry is a multicomponent, gummatized product with a wide range of biological activity, accelerating the growth and development of the animal organism. The «Relict $A^{\circledR}$ » is an environmentally friendly supplement that does not contain hormones and synthetic compounds. 
TABLE 2: The structure and nutritional value of the diet for laying hens

\begin{tabular}{l|c|l|c}
\multicolumn{2}{c}{ The composition of the recipe, \% } & \multicolumn{2}{c}{ Quality indicators } \\
\hline Corn & 40 & Exchange energy, kcal & 266.41 \\
\hline Wheat & 24.6 & Crude protein, \% & 15.03 \\
\hline Fish flour & 2.0 & Crude fiber, \% & 4.53 \\
\hline Monophosphate & 1.1 & Methionine + cystine, \% & 0.55 \\
\hline Chalk & 9.0 & Lysine, \% & 0.59 \\
\hline Salt & 0.3 & Calcium, \% & 3.35 \\
\hline Premix P-1-2 & 1.0 & Phosphorus, \% & 0.62 \\
\hline Sunflower meal & 17.0 & Sodium, \% & 0.16 \\
\hline Soybean meal & 5.0 & - & - \\
\hline Total & 100.0 & &
\end{tabular}

The chemical composition of the organic-mineral feed additive "Relict $A^{\circledR}$ " is presented in Table 3.

\section{Results and Discussion}

During the research period, the main zootechnical indicators were studied, such as the dynamics of changes in live weight, egg production, egg mass, safety, eatability and feed costs per unit of production, the safety of the poultry (Table 4).

From the obtained data it can be seen that at the beginning of the experiment, the live weight of the bird in all groups was almost the same. The inclusion of the studied additives contributed to an increase in the number of eggs per average layer in the second, third and fourth experimental groups by $17,5,26,6$ and $9,2 \%$, respectively, in comparison with the control indicator.

The content of harmful impurities does not exceed the maximum permissible norms in force in the Russian Federation.

The average daily feed intake per 1 average laying hen in all groups didn't differ significantly, which doesn't allow one to reveal any tendency. In this regard, the calculation of the costs indicator of feed for the production of one dozen eggs in the second, third and fourth experimental groups decreased by 15.6, 20.3 and 8.6\%, respectively, compared with the control, which amounted to $1.28 \mathrm{~kg}$. The egg mass in all groups was almost the same and corresponded to the age and physiology of the hens of this cross. Since a larger number of eggs was obtained from the experimental poultry, the rate of obtained egg mass from one laying hen increased in the second group by $16.3 \%$, in the third - by $25.2 \%$ and in the fourth - by $7.3 \%$ compared with the control group. 
TABLE 3: The chemical composition of the organo-mineral feed additives "Relict $A^{\circledR}$ "

Indicator
Moisture content, \%
Mass fraction of total nitrogen, \%
Mass fraction of crude fiber, \%
Mass fraction of crude ash, \%
Mass fraction of calcium, \%
Mass fraction, phosphorus, \%
The sodium content, $\mathrm{mg} / \mathrm{kg}$
The magnesium content, $\mathrm{mg} / \mathrm{kg}$
The potassium content, $\mathrm{mg} / \mathrm{kg}$
The iron content, $\mathrm{mg} / \mathrm{kg}$
The zinc content, $\mathrm{mg} / \mathrm{kg}$
The manganese content, $\mathrm{mg} / \mathrm{kg}$
The copper content, $\mathrm{mg} / \mathrm{kg}$
The cobalt content, $\mathrm{mg} / \mathrm{kg}$
Lead, mg / $\mathrm{kg}$
Arsenic, mg / kg
Cadmium, mg / kg
Mercury, mg / kg

\begin{tabular}{|c|c|}
\hline Results \\
\hline 4.5 \\
\hline 1.08 \\
\hline 2.2 \\
\hline 91.7 \\
\hline 0.63 \\
\hline 0.092 \\
\hline 94.08 \\
\hline 133.2 \\
\hline 673.6 \\
\hline 6502.5 \\
\hline 22.2 \\
\hline 50.2 \\
\hline 5.6 \\
\hline 3.6 \\
\hline 4.43 \\
\hline 6.49 \\
\hline 0.1 \\
\hline 0.01 \\
\hline
\end{tabular}

TABLE 4: Indicators of production of chicken eggs in the experiment for the 1st month of egg laying

Indicators
The age of laying the 1st egg, days
Eggs laid on a medium layer, pcs.
Preservation, \%
The average daily feed intake per 1 average
layer, $g$
The amount of feed for the production of 1
dozen eggs, kg
The mass of eggs, $\mathrm{g}$
Received egg mass from 1 laying hen, kg
Oviposition rate, \%
Production costs per head, rub.
Cost of feed on 1 head, rub.
Revenue from egg production per head, rub.
The production cost of 1 dozen eggs, rubles.
Profit per head per month, rub.
Profitability, \%
Note: ${ }^{*}$ - P<0.05; ${ }^{* *}$ - P<0.01

\begin{tabular}{|c|c|c|c|}
\hline \multicolumn{4}{|c|}{ Group } \\
\hline 1 & 2 & 3 & 4 \\
\hline 117 & 117 & 117 & 112 \\
\hline $22.9 \pm 1.3$ & $26.9 \pm 1.4^{*}$ & $29.0 \pm 1.0^{* *}$ & $25.0 \pm 1.6$ \\
\hline 100 & 100 & 100 & 100 \\
\hline 95.00 & 94.10 & 95.40 & 94.10 \\
\hline & & & \\
\hline 1.28 & 1.08 & 1.02 & 1.17 \\
\hline $53.80 \pm 0.54$ & $53.14 \pm 0.6$ & $53.3 \pm 0.49$ & $52.86 \pm 0.63$ \\
\hline 1.23 & 1.43 & 1.54 & 1.32 \\
\hline 71.70 & 84.20 & 90.60 & 78.10 \\
\hline 107.74 & 106.63 & 108.10 & 106.63 \\
\hline 75.42 & 74.64 & 75.67 & 74.64 \\
\hline 137.65 & 161.63 & 174.00 & 150.00 \\
\hline 32.90 & 27.70 & 26.10 & 29.90 \\
\hline 29.90 & 54.99 & 65.90 & 43.37 \\
\hline 21.72 & 34.02 & 37.87 & 28.91 \\
\hline
\end{tabular}


It should be noted that during the first month of the experiment, the intensity of laying eggs of hens in the control group was $71.7 \%$, and in the second, third and fourth experimental groups - higher by $12.5,18.9$ and $6.4 \%$, respectively. The proceeds from egg production per head in the groups receiving the studied supplement increased in the second group by $17.4 \%$, in the third group - by $26.4 \%$, in the fourth - by $9.0 \%$, compared with the control. In general, the profit received from 1 head per month from the experimental poultry was higher than that from the control by 25.0, 36.0 and 13.5 rubles, in groups, respectively. Thus, the profitability level in the first group amounted to $21.72 \%$, in the second - by $12.3 \%$ higher, in the third - by $16.15 \%$, in the fourth - by $7.19 \%$.

\section{Conclusion}

The use of the «Relict $A^{\circledR}$ 》 feed additive in laying hens rations contributed to an increase in the number of eggs per average laying hen, a decrease in the cost of feed for the 1 dozen eggs production, and a reduction in the time, the poultry reaches the peak egg laying intensity. Feeding the studied additive to laying hens allowed one to reduce the cost of 1 dozen eggs production in the experimental groups, and also increased the profitability of chicken eggs in comparison with the control.

\section{Acknowledgement}

The authors would like to thank their colleague for their contribution and support to the research. They are also thankful to all the reviewers who gave their valuable inputs to the manuscript and helped in completing the paper.

\section{Conflict of Interest}

The authors have no conflict of interest to declare.

\section{References}

[1] Petenko, A. I., et al. (2019). The Efficiency of Using Functional Feed Additives in Combined Feeds for Broiler Chickens. International Journal of Engineering and Advanced Technology, vol. 8, issue 6, pp. 5292-5294.

[2] Temiraev, R. B., et al. (2018). Effect of Mold Inhibitor and Adsorbent on Broilers Digestive Enzyme Activities and Meat Productivity with Reduced Risk of Aflatoxicosis. 
Journal of Pharmaceutical Sciences and Research, vol. 10, issue 11, pp. 2900-2902.

[3] Siegert, W., et al. (2020). Prececal Amino Acid Digestibility and Phytate Degradation in Broiler Chickens when using Different Oilseed Meals, Phytase and Protease Supplements in the Feed. Poultry Science, vol. 98, pp. 5700-5713.

[4] Lukyanov, N. V., et al. (2013). Humic Acids of Oxidized Brown Coals of Some Deposits in Russia and Mongolia. Bulletin of St. Petersburg State Technological Institute (Technical University), vol. 22, issue 48, pp. 053-055.

[5] Barylo, B. O., Gilmanova, M. V. and Grekhova, I. V. (2018). The Effect of Humic Preparations from Brown Coal and Lowland Peat on the Test Culture. Presented at Proceedings of the LII International Student Scientific and Practical Conference, March 15, 2018, Tyumen, Russia. Publisher: State Agrarian University of the Northern Trans-Urals (Tyumen), vol. 1, pp. 17-21.

[6] Gangadoo, S., et al. (2016). Nanoparticles in Feed: Progress and Prospects in Poultry Research. Trends in Food Science \& Technology, vol. 58, pp. 115-126.

[7] Qiu, J. L., et al. (2020). Organic Trace Minerals Improve Eggshell Quality by Improving the Eggshell Ultrastructure of Laying Hens During the Late Laying Period. Poultry Science, vol. 99, pp. 1483-1490.

[8] Savelyeva, A. V., et al. (2015). Investigation of the Composition and Properties of Humic Acids of Natural and Mechanochemically Oxidized Brown Coal. Chemistry of Solid Fuels, vol. 4, p. 3.

[9] Burchacka, E., Łukaszewicz, M. and Kułażyński, M. (2019). Determination of Mechanisms of Action of Active Carbons as a Feed Additive. Bioorganic Chemistry, vol. 93, p. 102804.

[10] Kanmaz, E. Ö. (2019). Humic Acid Formation during Subcritical Water Extraction of Food By-Products using Accelerated Solvent Extractor. Food and Bioproducts Processing, vol. 115, pp. 118-125.

[11] Khilko, S. L., Efimova, I. V. and Smirnova, O. V. (2011). Antioxidant Properties of Humic Acids from Brown Coal. Chemistry of Solid Fuels, vol. 6, pp. 3.

[12] Petrova, O. G., Kolberg, N. A. and Rubinsky, I. A. (2012). Characterization of Immunostimulants and their Classification, Agri-food Policy of Russia, vol. 6, pp. 69-71.

[13] Zou, C., et al. (2020). Comparison of Solid Phase Extraction Methods for the Measurement of Humic-Like Substances (HULIS) in Atmospheric Particles. Atmospheric Environment, vol. 225, p. 117370.

[14] Vasiliev, A. A., et al. (2018). The Value, Theory and Practice of Using Humic Acids in Animal Husbandry. Agrarian Scientific Journal. vol. 1, pp. 3-6. 
[15] Korsakov, K. V. (2018). The Effect of the Preparation of Humic Acids on the Hatchability of Hatching Eggs and the Quality of Hatched Young. Fundamentals and Prospects of Organic Biotechnology, vol. 4, pp. 27-30. 